\title{
Transparência: reposicionando o debate
}

Transparency: repositioning the debate

Transparencia: reposicionando el debate

\section{Robson Zuccolotto}

Doutor em Controladoria e Contabilidade pela Universidade de São Paulo

Professor do Departamento de Administração e Contabilidade da Universidade Federal de

Viçosa

Endereço: Rua Conde Luis Eduardo Matarazzo, n॰250, ap. JB 34, Vila São Silvestre

CEP: 05.356-000 - São Paulo/SP - Brasil

E-mail: robsonzuccolotto@gmail.com

Telefone: +55 (31) 3899- 2886 ou +55 (11) 2368-8012

\section{Marco Antonio Carvalho Teixeira}

Doutor em Ciências Sociais pela Pontifícia Universidade Católica de São Paulo.

Professor do Departamento de Gestão Pública da Fundação Getúlio Vargas de São Paulo

Endereço: Av. 9 de Julho, n॰ 2029 - $3^{\circ}$ andar, Bela Vista

CEP: 01.313-902- São Paulo/SP - Brasil

E-mail: marco.teixeira@fgv.br

Telefone: +55 (11) 37997960

\section{Edson Luiz Riccio}

Livre-docente em Sistemas de Informação pela Universidade de São Paulo

Doutor em Administração pela Universidade de São Paulo

Professor da Faculdade de Economia Administração e Contabilidade da Universidade de São

Paulo

Endereço: Av. Prof. Luciano Gualberto, no 908 - FEA3 - Butantã

CEP: 05.508-900 - São Paulo/SP - Brasil

E-mail: elriccio@usp.br

Telefone: +55 (11) 3091-5820, Ramal: 185

Artigo recebido em 11/07/2014. Revisado por pares em 23/02/2015. Reformulado em 10/03/2015. Recomendado para publicação em 08/04/2015 por Sandra Rolim Ensslin (Editora Científica). Publicado em 29/05/2015. 


\title{
Resumo
}

A crise da democracia representativa nas últimas décadas desencadeou um conjunto de reformas cuja finalidade era fortalecer a democracia. Independente do modelo de reforma, um tema central em todas elas era a necessidade de aumentar a accountability democrática. A ampliação da accountability traz consigo a necessidade de compreender outro tema que, além de atrair muita atenção nos últimos anos, tem sido usado, pela mídia e pela academia científica sem os devidos cuidados conceituais: a transparência. Nesse sentido, este trabalho realiza uma revisão da literatura internacional sobre os conceitos e as classificações da transparência com o objetivo de proporcionar aos pesquisadores nacionais a ampliação de conhecimento sobre esse campo de investigação e, por consequência, maior precisão conceitual e classificatória aos estudos sobre o tema. Além do conceito de cada perspectiva, sugere-se uma recomendação mínima do que analisar em cada uma delas. A sistematização dos conceitos e classificações permite aos pesquisadores compreender e avançar nas pesquisas, possibilitando ampliar a reflexão sobre transparência no contexto brasileiro, ainda que em perspectiva comparada.

Palavras-chave: Conceito de transparência. Classificações da transparência. Dimensões da transparência.

\begin{abstract}
The representative crisis of democracy in recent decades has triggered a number of reforms whose aim was to strengthen democracy. Regardless of the reform model, a central theme in all of them was the need to increase the democratic accountability. The expansion of accountability brings with it the need to understand another issue that, in addition to attracting much attention in recent years, has been used by the media and the scientific academy without due care concept: the transparency. In that sense, this paper conducts a review of the international literature on the concepts and classifications of transparency in order to provide national researchers expansion of knowledge about this research field and, consequently, greater conceptual and classification precision for studies on the subject. Beyond the concept of each perspective, it is suggested a minimum recommendation on what analyze in each one of them. The systematization of the concepts and classifications allows researchers to understand and advance the research, making it possible to expand the reflection on transparency in the Brazilian context, although in comparative perspective.
\end{abstract}

Keywords: Concept of transparency. Classifications of transparency. Dimensions of transparency.

\section{Resumen}

La crisis de la democracia representativa en las últimas décadas desencadenó un conjunto de reformas cuya finalidad era fortalecer la democracia. Independiente del modelo de reforma, un tema central en todas ellas era la necesidad de aumentar la accountability democrática. La ampliación de la accountability trae consigo la necesidad de comprender otro tema que, además de atraer mucha atención en los últimos años, ha sido usado, por los medios y por la academia científica sin el cuidado conceptual suficiente: la transparencia. En ese sentido, este trabajo realiza una revisión de la literatura internacional sobre los conceptos y las clasificaciones de la transparencia con el objetivo de proporcionar a los investigadores nacionales la ampliación de conocimiento sobre ese campo de investigación y, por 
consecuencia, mayor precisión conceptual y clasificatoria a los estudios sobre el tema. Además del concepto de cada perspectiva, sugerimos una recomendación mínima a respecto de lo que debe ser analizado en cada una de ellas. La sistematización de los conceptos y clasificaciones permite a los investigadores comprender y avanzar en las investigaciones, posibilitando ampliar la reflexión sobre transparencia en el contexto brasileño, aunque en perspectiva comparada.

Palabras clave: Concepto de transparencia. Clasificaciones de la transparencia. Dimensiones de la transparencia.

\section{Introdução}

Nos últimos anos, o debate sobre a transparência tem atraído muita atenção, tanto da opinião pública quanto dos meios acadêmicos, e o termo tem sido tomado continuamente como sinônimo de solução para muitos problemas existentes numa ordem democrática. Apesar de estar em evidência nos dias atuais, o termo transparência tem sua origem no século XIX, mas, somente no século XX, é que seu uso tomou o significado que conhecemos hoje, ou seja, está relacionado à política. No entanto, conforme destacam Michener e Bersch (2011, p. 1), quando se trata do conceito de transparência, ou sua definição, a maioria dos estudiosos escolhe o caminho mais simples, adotando definições estilizadas ${ }^{1}$ de transparência, ou assumem a postura de que "nós reconhecemos a transparência quando a vemos". Os autores destacam, ainda, que as pessoas falam sobre as coisas que são semitransparentes ou totalmente transparentes, mas não é exatamente claro o que elas significam. Em suma, os estudiosos não têm convergido para um termo com a intenção de estabelecer parâmetros ou medidas, da forma, por exemplo, como os teóricos da democracia têm feito com o termo democracia (como, por exemplo, DAHL, 2012; PRZEWORSKI; STOKES; MANIN, 1999). Essa omissão não só deixa uma lacuna crítica na literatura, como leva a transparência a um alongamento conceitual e a um neologismo impreciso e incomunicável.

Esse alongamento conceitual e neologismo impreciso e incomunicável acabam sendo transpostos para os veículos de comunicação e impactam também os trabalhos acadêmicos elaborados no Brasil. Em geral, os trabalhos acadêmicos que se destinam à avaliação da transparência dos governos o fazem de forma geral e, em pouquíssimos casos, delimitam o tipo ou classificação da transparência que se pretende estudar. De forma geral, os trabalhos misturam avaliações de transparência ativa com transparência passiva, de transparência nominal com efetiva, de visibilidade de informação com capacidade de inferência e, principalmente, misturam as perspectivas analíticas da transparência, avaliando ao mesmo tempo transparência contábil, transparência orçamentária, do processo de compras, midiática, ${ }^{2}$ etc.

Trabalhos realizados no Brasil (AKUTSU; PINHO, 2002; CRUZ et al., 2012; PINHO, 2008; RIBEIRO; ZUCCOLOTTO, 2014; ZUCCOLOTTO; TEIXEIRA, 2014) se propuseram

\footnotetext{
${ }^{1}$ O termo estilizado, na concepção utilizada por Michener e Bersch (2011), sugere que o termo transparência é modificado (suprimindo-se, substituindo-se e/ou acrescentando elementos ao termo) para que seja possível obter determinados resultados.

${ }_{2}^{2}$ Transparência midiática refere-se, neste trabalho, às informações divulgadas em meio eletrônico de acesso público como portais e sites na internet. 
a avaliar a transparência em âmbito subnacional, sendo louvável o esforço dos autores na tentativa de estabelecer medidas de transparência e estudá-la no contexto da consolidação democrática brasileira. Entretanto, esse esforço de mensuração, seguindo os padrões vigentes na pesquisa, misturaram diferentes perspectivas analíticas e, por vezes, ignoraram, total ou parcialmente, características importantes dessas perspectivas. Apesar dos esforços dos autores em medir a transparência, pouco se ajustou em termos de limites conceituais, como fizeram os autores Michener e Bersch (2011) por exemplo.

Buscando contribuir com a literatura nacional sobre o que Heald (2006) denomina de anatomia da transparência, este trabalho realiza uma revisão da literatura internacional sobre os conceitos e as classificações da transparência com o objetivo de proporcionar aos pesquisadores nacionais a ampliação de conhecimento sobre esse campo de investigação e, por consequência, maior precisão conceitual e classificatória aos estudos sobre o tema.

Adicionalmente, busca-se avançar nesse campo de pesquisa ao se propor uma classificação da transparência quanto às suas perspectivas, apresentando o conceito de cada uma dessas perspectivas, bem como o que se deve analisar em cada uma delas.

\section{Plataforma teórica}

\subsection{Transparência: um conceito em construção}

Mesmo que o conceito de transparência seja cada vez mais encontrado na literatura acadêmica, seu significado ainda permanece fluido. Em parte, isso se deve ao fato de esse conceito ser usado em diferentes aspectos relacionados ao fluxo das informações.

$\mathrm{Na}$ literatura sobre conflitos entre países, um país é transparente se outro conseguir obter informações sobre as preferências da sua sociedade e o seu respectivo apoio às ações de governo (SCHULTZ, 1999). Por outro lado, na literatura sobre regimes internacionais ${ }^{3}$, transparência refere-se às informações que os países oferecem aos organismos internacionais, e, em estudos sobre corrupção, transparência se refere à existência de ferramentas e instituições que contribuam para a redução das práticas de corrupção em um país. Já na Ciência Política, o conceito de transparência está associado à divulgação de informações por parte dos governos para atores internos e externos (GRIGORESCU, 2003) e sua consequente utilização como instrumento de responsabilização (accountability ${ }^{4}$ ) dos agentes públicos quando estes adotam algum procedimento inadequado ao bom uso dos recursos públicos (LOUREIRO; TEIXEIRA; PRADO, 2008).

\footnotetext{
${ }^{3}$ Um regime, conforme definido por Krasner (2012, p. 186), é um conjunto explícito ou implícito de "princípios, normas, regras e procedimentos de tomada de decisão em torno da qual as expectativas dos atores sociais convergem em uma determinada área temática". Essa definição é intencionalmente ampla e abrange as interações humanas que vão desde as organizações formais (ONU, FMI, etc.) até grupos informais (associações não formalizadas).

${ }^{4}$ Apesar de o conceito de accountability pressupor a existência de transparência, o conceito de accountability não é sinônimo de transparência. De acordo com Prado, Ribeiro e Diniz (2012), o conceito de accountability é mais amplo, pois atinge não apenas a prestação de contas e a publicidade das ações dos governos, mas também a existência de mecanismos institucionais de controle da administração pública que possam gerar incentivos ou sanções, caso os agentes públicos cumpram ou não suas obrigações. A transparência das informações públicas é uma das etapas da accountability, assim como a prestação de contas e a responsabilização dos governantes.
} 
Aplicado ao campo da Administração Pública, Birkinshaw (2006) diz que a transparência pode ser entendida como a gestão dos assuntos públicos para o público, e Black (1997) completa a definição declarando que transparência é o oposto de políticas opacas, em que não se tem acesso às decisões, ao que elas representam, como são tomadas e o que se ganha ou se perde com elas.

Do ponto de vista normativo, Oliver, como citado em Meijer (2009, p. 258), descreve que "a transparência faz-se a partir de três elementos: um observador, algo disponível a ser observado e os meios ou métodos para se realizar a observação". Já Moser (2001, p. 3) a define como a "abertura dos procedimentos de funcionamento imediatamente visíveis para aqueles que não estão diretamente envolvidos (o público) para demonstrar o bom funcionamento de uma instituição".

A dificuldade em se estabelecer um conceito abrangente, que ultrapasse os limites de cada área do conhecimento levou, também, ao uso do termo transparência como sinônimo de abertura e vigilância, mesmo que, nem sempre, isso seja verdadeiro.

\subsection{Relação triangular entre transparência, abertura e vigilância}

Conforme destaca Heald (2006, p. 25), uma questão importante a se estudar quando se trata da transparência é a relação triangular entre transparência, abertura e vigilância. A primeira questão destacada pelo autor é se uma clara distinção pode ser estabelecida entre transparência e abertura e ele destaca que, em termos gerais, a resposta parece ser negativa. Para exemplificar essa negativa, o autor enfatiza que o Comitê de Nolan, no Reino Unido, formulou, em 1995, os sete princípios da vida pública, que deveriam ser aplicados em todo o serviço público, quais sejam: abnegação, integridade, objetividade, accountability, abertura, honestidade e comando. $\mathrm{O}$ autor complementa dizendo que a abertura está intimamente relacionada à transparência, embora não signifique, conceitualmente, a mesma coisa.

Como se observa no Nolan Committee (1995, p. 14), “os detentores de cargos públicos deveriam permitir que todas as suas ações e decisões fossem abertas e que o sigilo apenas seria permitido quando o interesse público claramente demandasse". Heald $(2006,25)$ destaca que, se o Comitê de Nolan tivesse sido elaborado em 2005 em vez de em 1995, "o termo transparência substituiria o termo abertura como um dos sete princípios". Nesse sentido, o autor afirma que transparência parece ter se transformado no termo preferido na atualidade, embora existam muitas ocorrências do termo transparência e abertura como se tivessem significados distintos.

Birkinshaw (2006, p. 190) considera que abertura e transparência são próximas em significado e ambas transmitem alguma coisa maior que acesso à informação governamental. De acordo com esse autor, "abertura significa concentrar-se no processo que nos permite ver as operações e atividades do governo no trabalho - sujeita... às isenções necessárias". Na visão desse autor, a transparência vai além da abertura, uma vez que considera que tanto o processo de elaboração das políticas públicas quanto sua implementação devem ser conduzidas da forma mais aberta possível. Larsson (1998, p. 40) apresenta visão similar ao afirmar que a "transparência se estende além da disponibilidade de informações para abraçar a simplicidade e compreensão". É possível, por exemplo, que uma organização esteja disponibilizando seus documentos e procedimentos para acesso público e, contudo, não seja transparente, uma vez que a informação é percebida como incoerente pelos cidadãos (os receptores não conseguem compreender e processar a informação). 
A segunda questão se refere à relação entre transparência/abertura e vigilância ${ }^{5}$. Um ponto óbvio sobre vigilância, de acordo com Heald (2006, p. 26), é que "alguém ou alguma coisa está fazendo a vigilância e isso explica porque o termo carrega um sentido de ameaça". Nesse sentido, a transparência pública pode auxiliar a sociedade na vigilância das ações dos governos, mas não assegura a responsabilização dos gestores públicos se outros mecanismos democráticos não existirem. De qualquer forma, as ideias de transparência, quando associadas à ideia de visão e translucidez, denotam que alguém está sendo observado, visto não existir barreiras visuais entre o observado e o observador e isso, por si só, cria uma ideia de vigilância.

Voltando à discussão denominada por Heald (2006) de anatomia da transparência, e tomando transparência como essa relação triangular (transparência, abertura e vigilância), apresenta-se, na próxima seção, as diversas conceituações e classificações atinentes à transparência.

\subsection{Classificações da transparência}

Esse tópico tem por objetivo realizar uma revisão da literatura internacional sobre as diversas classificações da transparência. $\mathrm{O}$ objetivo aqui não é, certamente, esgotar o tema, mas identificar as principais classificações existentes e apresentá-las ao leitor com a finalidade de reposicionar o debate sobre transparência. Uma vez que o conceito de transparência ainda é fluido e não foi apropriado por nenhuma área do conhecimento, poucos autores, até o momento, se aventuram na difícil de tarefa conceituar o termo. Da mesma forma que o conceito, as classificações dos diversos tipos, direções e variedades da transparência, também têm sido explorados por poucos autores. Nesse sentido, apresenta-se, a seguir, as principais classificações da transparência.

\subsubsection{Direções de transparência}

Conforme destacado anteriormente, esse trabalho se propõe a revisar os conceitos e classificação da transparência e não de accountability. Como já foi destacado também, os conceitos de transparência e accountability não devem ser confundidos, uma vez que accountability vai além da transparência, pois atinge não apenas a prestação de contas e a publicidade das ações dos governos, mas também a existência de mecanismos institucionais de controle da administração pública que possam gerar incentivos ou sanções, caso os agentes públicos cumpram ou não suas obrigações. A transparência das informações públicas é uma das etapas da accountability, assim como a prestação de contas e a responsabilização dos governantes (PRADO et al., 2012).

Adicionalmente, apesar de as discussões sobre accountability já usarem as classificações de "accountability vertical" e "accountability horizontal" (O'DONNELL, 1998), deve ficar claro que não se trata da mesma classificação de direção que abordaremos a seguir, uma vez que o que discutimos neste trabalho é a transparência e não a accountability.

Assim, no tocante à transparência, de acordo com Heald (2006), nos debates relacionados aos benefícios e custos desta (transparência) para o Estado, devem ser

\footnotetext{
${ }^{5}$ Vigilância pode ser entendida também como fiscalização. No texto, utiliza-se a palavra vigilância por denotar a vigilância do povo sobre os governos, venha essa vigilância das entidades de fiscalização, das entidades da sociedade civil organizada ou diretamente do cidadão.
} 
consideradas quatro direções. As duas primeiras (Transparência para cima e Transparência para baixo) referem-se ao que o autor denominou de Transparência Vertical, enquanto a Transparência de fora para dentro e a Transparência de dentro para fora se referem ao que o autor denominou de Transparência Horizontal. Essas conceituações são detalhadas com mais profundidade nos itens a seguir.

A Transparência para cima (vertical) pode ser concebida tanto em termos de relacionamentos hierárquicos como da análise principal-agente que subsidia a maioria dos modelos econômicos. Transparência ascendente significa que o superior/principal pode observar a conduta, o comportamento, e/ou os resultados dos subordinados hierárquicos/agentes. Nesse sentido, os agentes fornecem informações úteis para que o principal possa monitorá-los. Esse modelo parece adaptar-se mais às análises de fluxo informacional entre burocracias e governo, uma vez que, para analisar a efetividade de suas políticas, os eleitos precisam monitorar os burocratas.

A Transparência para baixo (vertical) ocorre quando os governados podem observar a conduta, o comportamento e/ou resultados de seus governantes. $\mathrm{O}$ direito dos governados em relação aos seus governantes figura, na teoria e na prática democrática, frequentemente, sob a tutela da accountability ${ }^{6}$.

Em uma análise da accountability no setor público, White e Hollingsworth (1999) definiram o governo como agente e o eleitor (povo) como principal. Heald (2006, p. 27) destaca que, embora "de uma perspectiva constitucional, possa parecer estranho que em uma democracia o governo seja visto como o agente e o povo como principal, essa interpretação pode ser bastante esclarecedora para a análise de transparência" sob o ponto de vista democrático.

As direções anteriormente abordadas não são excludentes, podendo coexistir em qualquer nível de governo. Além disso, quando há convergência entre essas duas direções de transparência, diz-se que ocorre a transparência vertical simétrica (ou transparência recíproca) e, ocorrendo o oposto, observa-se ausência ou assimetria de transparência vertical (indisponibilidade de informações entre eleitos e eleitores).

Importante destacar, ainda, que, em uma estrutura democrática, essas classificações são de extrema relevância, visto que o fluxo informacional deverá ocorrer tanto para cima (quando os burocratas prestam contas aos políticos sobre a efetividade da implementação das políticas) quanto para baixo (quando o representante eleito (executivo ou legislativo) prestará contas ao representado - população).

A Transparência para fora (horizontal) ocorre quando o subordinado hierárquico consegue observar o que está acontecendo além da organização. A habilidade de ver além da organização é fundamental para uma organização compreender seu ambiente e monitorar o comportamento de seus pares ou competidores.

Essa direção da transparência é primordial em estruturas federativas, uma vez que uma unidade subnacional necessita ver além de si mesma, ou seja, precisa acompanhar o movimento dos pares para dimensionar suas estratégias políticas, econômicas e orçamentárias.

\footnotetext{
${ }^{6} \mathrm{O}$ termo accountability é definido, neste trabalho, como a construção de mecanismos institucionais pelos quais os governantes são constrangidos a responder, ininterruptamente, por seus atos ou omissões perante os governados. Para melhor compreensão do termo accountability, ver Bessette (2001); Campos (1990); Pinho e Sacramento (2009) e Przeworski et al. (1999). 
A Transparência para dentro (horizontal) ocorre quando aqueles que estão fora da organização conseguem observar aquilo que ocorre em seu interior. Transparência para dentro é relevante para legislações sobre liberdade de informação e esse direcionamento de transparência é que possibilita os mecanismos de controle social por meio de legislações que determinam padrões de comportamento (como, por exemplo, a Lei de Responsabilidade Fiscal). Uma questão importante na Transparência para dentro é que ela traz consigo uma associação muito forte com vigilância, levando a uma discussão sobre os limites desse tipo de transparência para que não seja invasiva à privacidade do cidadão ou do governante.

Na Figura 1, adaptada de Heald (2006), pode-se visualizar com mais nitidez estas quatro direções e as relações existentes entre elas.

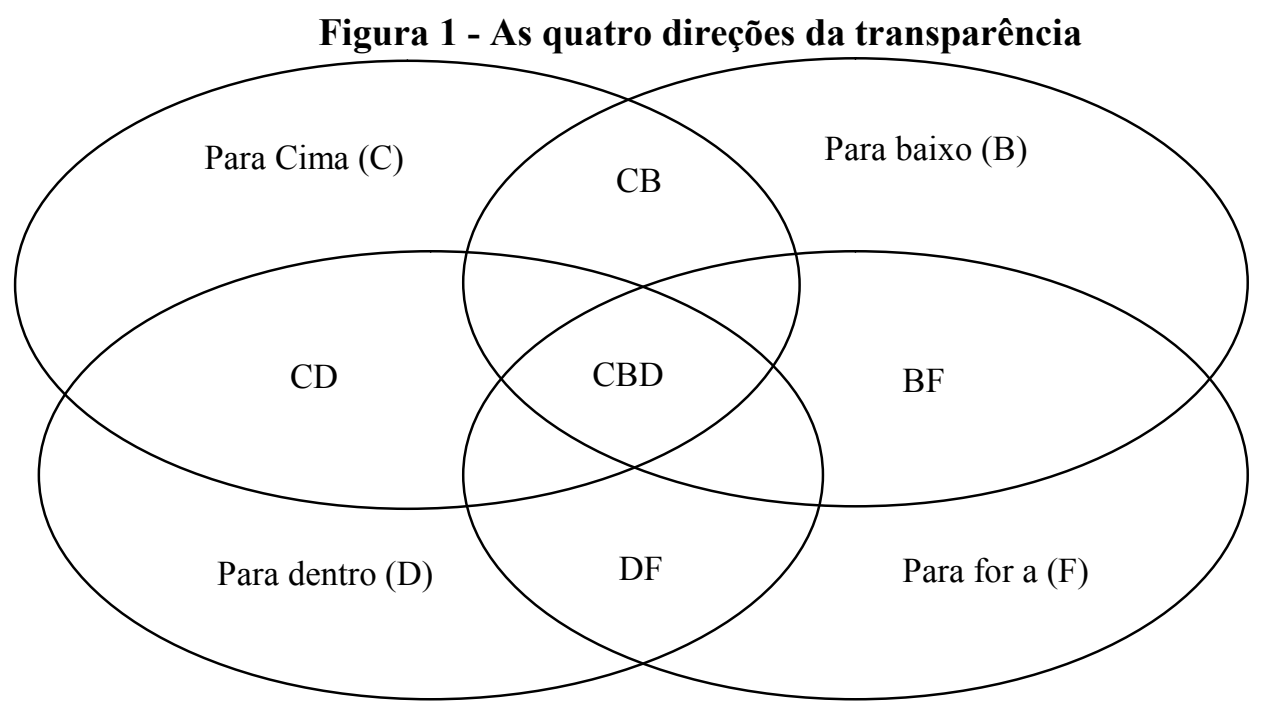

Fonte: Adaptado de Heald (2006).

Importante destaque deve ser dado à relação existente entre essas duas últimas direções da transparência, uma vez que, para que se veja além da organização (Transparência para fora), é necessário que tanto o ente quanto os seus pares permitam-se serem vistos (Transparência para dentro) e disso resulta grande parte das regulações sobre exigências mínimas de mecanismos e regras de transparência.

Por isso, Heald (2006) destaca que, quando a Transparência para fora e a Transparência para dentro coexistirem, se diz ocorrer a transparência horizontal simétrica. Por outro lado, a transparência horizontal estará completamente ausente ou será assimétrica caso umas das duas direções esteja ausente ou incompleta. A área representada por (CB) corresponde à Transparência vertical simétrica; já na interseção representada por (DF), verifica-se a existência de Transparência horizontal simétrica. A área que corresponde à (CBDF) representa a coexistência das quatro direções de transparência simultaneamente.

Hood (2006, p. 28) acrescenta que "se ocorrer a interseção das quatro direções da transparência tem-se a transparência completamente simétrica. Neste estágio nenhuma avaliação normativa do desejo das diferentes áreas será feito e isso explica porque as visões sobre transparência são, frequentemente, ambivalentes na prática".

Como se observa, a classificação da transparência, além de impor limites ao uso do termo, permite melhorar o potencial explicativo das pesquisas no campo. No entanto, além

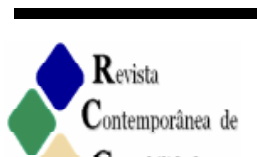

ISSN 2175-8069, UFSC, Florianópolis, v. 12, n. 25, p. 137-158, jan./abr. 2015

Contabilidade 
dos limites e potencialidades verificados na classificação das direções da transparência, é importante também compreender suas diversas variedades, conforme se verifica no tópico a seguir.

\subsubsection{Variedades de transparência}

Heald (2006) define as variedades de transparência de acordo com suas variáveis dicotômicas: transparência de eventos versus de processos, transparência retroativa versus tempestiva e transparência nominal versus efetiva. Essas variedades serão discutidas na sequência.

\subsubsection{Transparência de eventos versus de processos}

Inicialmente, apresenta-se a distinção entre a transparência de eventos e de processos, conforme é demonstrado na Figura 2.

A transparência dos eventos é representada pelos objetos: inputs, output e resultado, enquanto a dos processos é composta por aspectos processuais e operacionais. Analisando-se os eventos, tem-se: inputs são representados pelos tradicionais sistemas públicos de despesa, os outputs podem ser mensurados pelo nível de atividade do setor (como os número de cirurgias realizadas) e o resultado é de difícil avaliação, pois envolve questões subjetivas como satisfação e medidas de deterioração, entre outros fatores (como, por exemplo, se a qualidade do atendimento nas unidades de emergência melhorou).

Os sistemas atuais de avaliação da administração pública são baseados em inputs, mas recentemente tem-se enfatizado a necessidade de avaliá-la, considerando a quantidade e a qualidade dos serviços prestados (outputs e resultados). Todavia essas tentativas de medida ainda são controversas, questionáveis e subjetivas. Mesmo assim, os eventos são mais facilmente mensuráveis do que os processos.

Para que seja possível a transição entre os eventos, são necessários os processos de transformação e de associação. Embora não sejam mensuráveis como os eventos, podem ser descritos caso a informação esteja disponível. Geralmente os processos de transformação são mais bem compreendidos que os de associação, visto que suas variáveis, apesar de mais imprevisíveis, podem ser mais facilmente descritas e compreendidas (HEALD, 2003). Destaca-se que, mesmo que haja determinada facilidade na descrição dos processos, poucos trabalhos estudaram essa variedade da transparência. 
Figura 2 - Transparência de Eventos versus Transparência de Processos

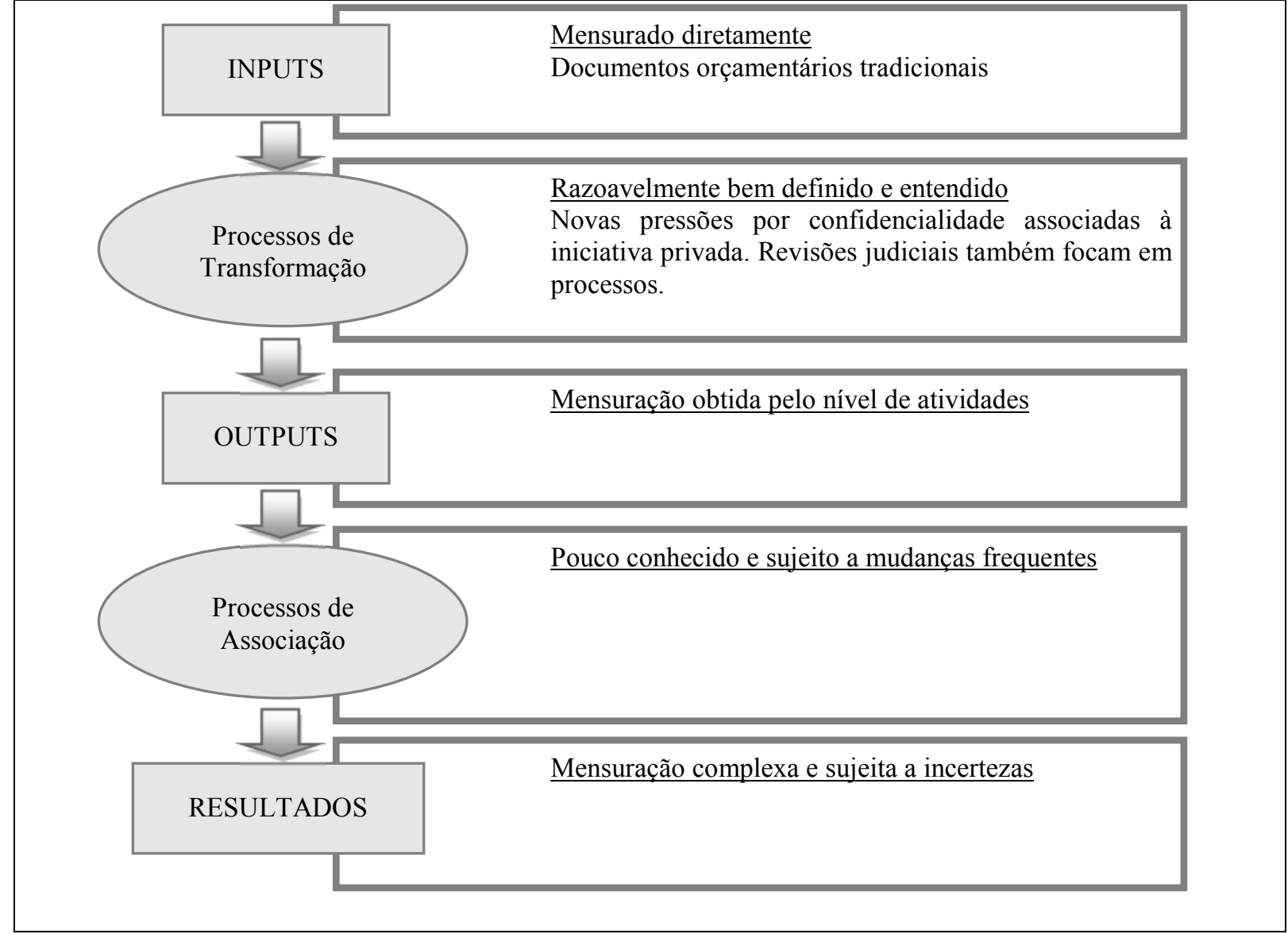

Fonte: Adaptação de Heald (2006, p. 30).

Para que o acompanhamento da administração pública esteja focado somente em eventos de transparência (inputs, outputs e resultado), os valores obtidos têm que gerar medidas suficientemente confiáveis para possibilitar a eficiência das políticas públicas. Nesse sentido, Michener e Bersch (2011) destacam que as informações, além de estarem disponíveis, precisam ser capazes de permitir inferências por parte dos diversos usuários que os consultam. Em regra, para garantir a confiabilidade da inferência, utilizam-se pareceres de especialistas ou de auditores.

Ainda no que se refere às variedades da transparência, tem-se a questão da tempestividade e da retroatividade das informações. Nesse sentido, a disponibilidade dos dados pode ocorrer tempestivamente, como no caso de evidenciação da execução orçamentária com base nos artigos da Lei Complementar n. 131, quanto retroativamente, como no caso de balanços e relatórios anuais. Essas duas formas de transparência serão discutidas no item a seguir.

\subsubsection{Transparência retroativa versus tempestiva}

Transparência retroativa refere-se à disponibilização ex post, em intervalos periódicos, das informações sobre a gestão dos recursos públicos. Esses dados sobre a avaliação do desempenho do Estado podem ser manipulados e referem-se a fatos já ocorridos os quais não 
podem ser modificados ou ajustados. Na verdade, percebe-se que o período abordado no disclousure é cíclico, há sempre um atraso informacional, e a sociedade não participa das decisões (HEALD, 2006). Como exemplo, pode-se citar a publicação dos Relatórios Resumidos da Execução Orçamentária (bimestral) e Relatório da Gestão Fiscal (quadrimestral).

Já a transparência tempestiva, de acordo com Heald (2006, p. 33), "é relativa ao contínuo acesso aos processos internos da administração e à disponibilidade de informações em tempo real". Assim, as decisões e operações do Estado podem ser modificadas significativamente de acordo com a participação social, o que melhora o seu desempenho nas tarefas fundamentais. Percebe-se, nesse modelo, mais transparência e fortalecimento do controle social. Ilustrativamente, tem-se o orçamento participativo e as divulgações em tempo real das informações da execução orçamentária.

Obviamente, um sistema baseado na transparência em tempo real é muito mais oneroso para a administração do que outro em que predomina a transparência retroativa. Logo, cabe ao Estado escolher qual dos dois modelos adotar, utilizando como parâmetro as características de cada atividade e de cada processo e, ainda, a circunstância em que ocorrem. Importante observar que a escolha de um determinado sistema poderá melhorar os níveis de transparência ou apenas aumentar o volume de informação divulgada sem, tampouco, aumentar a transparência. Nesse sentido, Heald (2006) destaca que é necessário verificar se os mecanismos adotados pelos Estados estão provendo transparência efetiva ou nominal.

\section{3.2.3 Transparência nominal efetiva}

Heald (2006) afirma que para haver transparência efetiva, os receptores das informações disponibilizadas pelo governo devem ser capazes de processá-las, compreendêlas e utilizá-las. Quando a informação é apenas divulgada e não é assimilada pelo cidadão, observa-se a existência de transparência nominal. Isso quer dizer que o governo teve a intenção de ser transparente, mas efetivamente não conseguiu. Associando o pensamento de Heald (2006) à conceituação proposta por Michener e Bersch (2011), pode-se afirmar que, na transparência efetiva, os receptores devem ser capazes de inferir algo com base na informação publicada, ou seja, a informação permite fazer inferências, ao passo que apenas publicá-la (visibilidade) não caracteriza efetivamente a transparência.

A divergência entre a transparência nominal e a transparência efetiva é denominada de ilusão de transparência, conforme demonstra a Figura 3. Essa ilusão é comprovada quando os índices que medem o nível de transparência parecem aumentar e, na realidade, estão diminuindo. Alguns fatores que contribuem para essa situação são: Orçamento (LOA) como simples peça orçamentária e legislativa, liberação de informações para favorecimento de um determinado grupo (fraudes em licitações), manipulação de dados sobre as dívidas do ente público, entre outros. 
Figura 3 - Ilusão de transparência

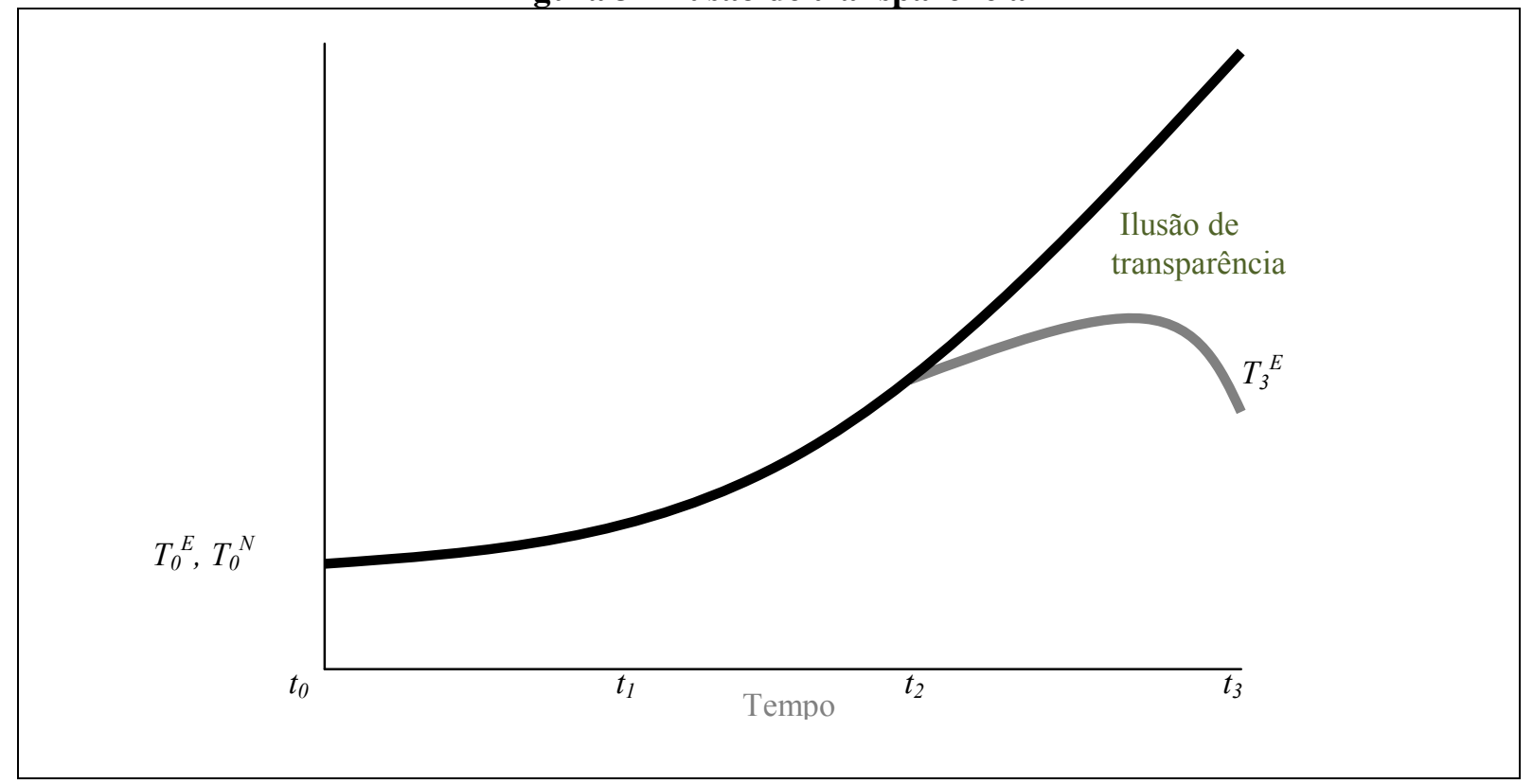

Fonte: Adaptado de Heald (2006).

\subsubsection{A transparência quanto à iniciativa}

No que se refere à iniciativa da transparência, Yazigi (1999, p. 26) escreve que "el acceso ciudadano oportuno, suficiente y garantizado a información relativa al desempeño de las funciones públicas, se hace posible distinguir dos tipos de transparencia: la transparencia activa y la transparencia pasiva".

A Transparência ativa consiste na difusão periódica e sistematizada de informações sobre a gestão estatal. Resulta de ações voluntárias dos gestores públicos ou de obrigações legais impostas aos órgãos do Estado, determinando que sejam publicadas informações necessárias e suficientes para que a sociedade possa avaliar o desempenho governamental. São exemplos dessas informações: explicação sobre as funções e atividades do governo, propostas e objetivos da gestão, dotações orçamentárias, indicadores de desempenho de gestão, sistemas de atendimento ao público, etc., e devem ser estruturadas de forma que permitam a comparação entre os exercícios (YAZIGI, 1999)

De acordo com Yazigi (1999), a Transparência ativa é um instrumento fundamental para a modernização do Estado, pois explicita os compromissos governamentais para que possam ser reclamados posteriormente como direitos sociais. Além da publicação dos indicadores de desempenho do serviço público e dos balanços institucionais, tem-se exigido a disponibilidade em uma página de web de informações sobre os serviços prestados, dados e valores mais relevantes da gestão, indicadores de desempenho, entre outras, com a finalidade de facilitar o controle social, permitindo a avaliação da administração atual, bem como acompanhar a evolução dos serviços públicos ao longo do tempo.

A Transparência passiva, por sua vez, refere-se à obrigação do Estado em conceder a todos os cidadãos que o requeiram o acesso tempestivo aos documentos oficiais, salvo aqueles que estiverem legalmente protegidos por motivo de segurança nacional, investigação pública, direito de terceiros, etc. A regra geral é o livre acesso, sendo o sigilo a exceção. Deve-se 
destacar, ainda, que o sigilo pode ser questionado judicialmente, cabendo à administração pública comprovar legalmente o impedimento (YAZIGI, 1999). Um exemplo recente desse modelo no Brasil é a Lei de Acesso à Informação (LAI).

Mesmo que diversos organismos internacionais como o Banco Mundial, o FMI, a OCDE, entre outros, tenham desenvolvido guias para transparência, muitos órgãos estatais ainda não possuem uma distinção legal clara entre o que deve ser informado constantemente para o público (Transparência ativa) e aquilo que deve ser disponibilizado somente quando solicitado pelo cidadão (Transparência passiva) e ainda as informações e documentos que devem ser indefinidamente mantidos à margem do conhecimento público (YAZIGI, 1999).

Adicionalmente, deve-se destacar que, mesmo que legislações específicas obriguem a divulgação de determinadas informações, muitos entes da federação acabam descumprindo as regras, dado que nem sempre as penalidades são significativas. Para Yazigi (1999) uma vez vencidas as resistências naturais das pessoas que querem manter uma barreira entre o Estado e a sociedade, aquelas sociedades que avançarem pelo caminho da transparência desfrutarão das vantagens dos fundamentos da democracia: conhecimento, poder e participação dos cidadãos.

Seguindo a classificação apresentada, pode se destacar Oliver, como citado em Meijer (2009), o qual faz uma distinção entre a velha e a nova transparência. Ele discute que a velha transparência era bastante passiva, ou seja, os fatos públicos só se tornavam acessíveis se as pessoas manifestassem interesse em perguntar. "A nova transparência, em contraste, é mais ativa e pode ser definida como disclosure ativo, o que implica em chamar a atenção da sociedade para as ações intencionais e não intencionais dos gestores" (MEIJER, 2009, p. 4)).

Fung, Graham e Weil (2007) fazem uma distinção semelhante entre a primeira e segunda geração de transparência. A primeira geração de transparência é bastante passiva e tem como foco rigth-to-know. A segunda geração é mais ativa e tem como metas reduzir os riscos e melhorar o desempenho da instituição para atendimento dos anseios populares. Nesse cenário, os autores conseguem vislumbrar uma terceira geração de transparência transparência participativa - que consiste na colaboração entre governo e sociedade.

Para Hood (2006), uma característica comum a essas formas modernas de transparência é que elas se realizam por meio de mídias. Essa forma não é direta e se distancia da forma tradicional de transparência em que as decisões emergem de debates face a face nas audiências públicas. Já na visão de Berends, como citado em Meijer $(2009$, p. 6), "está sendo criado um novo tipo de transparência - a transparência virtual (ou midiática) - em que a sociedade tem informações sobre as ações do Estado, mas não há contato (físico, presencial) com ele (interação)". O autor considera que a transparência midiática pode ter consequências importantes, como, por exemplo, tornar-se uma via de mão única (contrariando o seu propósito) e produzir informação descontextualizada (dados sem o seu contexto geram desinformação). Na percepção de Postman (1993, p. 78), o desenvolvimento dos meios de comunicação pode fazer com que a "informação que é disponibilizada indiscriminadamente, em grande volume e em alta velocidade, dirija-se em particular a ninguém, e seja desprovida de contexto, significado ou propósito". Dessa afirmação podemos inferir a importância dos relatórios periódicos, com informações sobre os planos orçamentários, sua execução e desempenho, sempre contextualizados e comparativos.

Por outro lado, Oliver, como citado em Meijer (2009, p. 10), "relaciona diretamente a propulsão da transparência com o desenvolvimento das tecnologias de informação". Ele 
discute que o uso de combustíveis tecnológicos (internet e $w w w)^{7}$ facilita o acesso e a análise da informação, e como resultado tem-se o baixo custo da informação e sua distribuição em níveis globais aos indivíduos (que reagem imediatamente a essa informação).

Considerando a tecnologia e a transparência como frutos da era da informação, representando conceitos de modernização, a transparência midiática insere-se como mecanismo promotor do controle social e consequentemente da consolidação democrática, em sociedades modernas. Resgatando o pensamento de Bentham, Meijer (2009) defende a publicação das contas públicas, bem como de todos os atos governamentais que, nesse novo cenário, deveria ser feita em site de Governo como meio para evitar omissão direta e aumentar a confiança dos cidadãos em seus governantes. Transparência não é algo completamente novo, a abertura do governo para a sociedade é um processo longo, mas sua importância tem aumentado e há atualmente uma preocupação em gerar informação confiável para a sociedade.

Além da preocupação com a confiabilidade, Larsson (1998) destaca que a transparência se estende além da disponibilidade de informações (confiáveis) para abraçar, também, a simplicidade e compreensão. Nesse sentido, Michener e Bersch (2011), buscando conceituar a qualidade da transparência, introduzem duas dimensões importantes ao conceito de transparência: visibilidade e inferability. Essas dimensões são apresentadas e discutidas no tópico a seguir.

\subsubsection{As dimensões conceituais da transparência}

De acordo com Michener e Bersch (2011), a palavra transparência abrangia tanto um significado literal como figurado antes de ganhar proeminência como um slogan administrativo para tudo que é aberto, confiável, participativo e passível de responsabilização. O significado literal era sustentado na ideia de luz e visão (visibility), enquanto o significado figurado representava tudo aquilo que podia ser inferido (inferability) com algum grau de facilidade e acurácia.

Como se observa, os conceitos são apresentados de forma contínua. A ideia de que uma informação é mais visível ou possui mais capacidade de inferência está em consonância com a noção de que alguns governos são mais transparentes que outros. Como a visibilidade e a inferability representam parte constituinte da transparência, elas são também, em algum grau, uma sobreposição de conceitos, ou seja, elementos da visibilidade podem ter relevância para a inferability.

Buscando elucidar os conceitos de visibilidade e capacidade de inferência, o tópico a seguir apresenta e discute os referidos conceitos.

\subsubsection{Visibilidade da informação}

A visibilidade da informação é uma das duas condições necessárias para a transparência. Para ser visível, a informação deve ser razoavelmente completa e encontrada com relativa facilidade. Nesse sentido, Michener e Bersch $(2011$, p. 8) destacam que "transparência diz respeito à informação e, se a informação não é visível perde sua

\footnotetext{
${ }^{7}$ Internet é um conjunto de redes de computadores que utilizam o protocolo TCP/IP para se comunicar entre si, e Web é um termo simplificado de World Wide Web, que é entendido como teia mundial de larga escala. A Web é um ambiente onde os documentos são publicados, disponibilizados e acessados.
} 
relevância”. No entanto, só porque algo é público, não significa que seja visível, uma vez que, para ser visível, a informação deve refletir um grau elevado de integridade. Assim, a informação incompleta diminui o grau de transparência, e o dilema óbvio nessa situação é a incerteza de completude, ou seja, quem garantirá aos cidadãos que a informação é completa? A resposta a essa pergunta passa pelo destaque da importância das Instituições Supremas de Auditoria, que atestarão a veracidade e confiabilidade das informações visíveis, sobretudo aquelas de aspectos orçamentários e contábeis. Atenção especial deve ser dispensada às informações e aos quadros resumos divulgados espontaneamente pelos entes, visto que, em alguns casos, essa divulgação tem a intenção mais de confundir do que esclarecer.

Continuando sua explanação sobre as características da transparência, Michener e Bersch (2011, p. 9) destacam que a "visibilidade também incorpora uma segunda característica: a probabilidade de encontrar informações". Além disso, outra característica relacionada é a possibilidade de se cruzarem as informações de forma natural, sem efetivamente ter que procurá-las. Em suma, a visibilidade da informação - que consiste em sua plenitude e na probabilidade de ser encontrada - representa uma das duas condições necessárias a sua existência.

\subsubsection{Capacidade de inferência}

Outra condição necessária para a transparência é o grau de inferência que se pode ter com as informações divulgadas. Inferability significa a medida pela qual a informação disponível pode ser usada para se fazer inferências ${ }^{8}$. Assim, inferability está relacionada à qualidade da informação ou dados. Se os dados são imprecisos, ou obscurecem a informação subjacente, eles põem em questão a habilidade de fazer inferências a partir de tais informações e, por consequência, põem em dúvida o que foi divulgado. Assim, informações incompreensíveis ou ininteligíveis são inverificáveis e, certamente, não devem ser utilizadas para se fazer inferências (MICHENER; BERSCH, 2011).

Nesse sentido, esses autores destacam que, para que a informação seja considerada transparente, ela não deve ser apenas visível, mas deve, também, permitir ao seu usuário fazer inferências a partir delas e relatam que uma dimensão crítica da inferability é o grau em que os dados são mediados. Adicionalmente, relatam que a mediação ocorre em graus, uma vez que os dados sobre a poluição de uma cidade podem ser mediados por cientistas, técnicos do governo e, até mesmo, por políticos (eleitos ou nomeados) antes de serem apresentadas ao público. A mediação pode ocorrer também por meio de terceiros, tais como laboratórios privados. Finalmente, dados brutos sobre poluição podem ser mediados por meio de escores ou dispositivos que tornem a sua compreensão mais fácil aos leigos. Mesmo tornando mais fácil a compreensão, os autores relatam que a mediação pode afetar a habilidade de verificar os dados, e isso afeta sua usabilidade.

\footnotetext{
${ }^{8}$ O termo inferência tem inúmeras interpretações. Por exemplo, King, Keohane e Verba (1994, p. 46) definem inferência como: "o processo de usar os fatos que conhecemos para aprender sobre os fatos que não conhecemos. Os fatos que não conhecemos são o objeto de perguntas das nossas pesquisas, teorias e hipóteses. Os fatos que conhecemos são nossos (quantitativos e qualitativos) dados ou observações". Inferência estatística, por outro lado, refere-se a fazer generalizações sobre a população com base em informações da amostra. Michener e Bersch (2011, p. 9) usam uma definição que inclui não só a compreensão de inferência estatística, mas uma definição mais ampla que inclui a capacidade "para deduzir ou concluir (informação) a partir de evidências e raciocínio, e não de declarações explícitas".
} 
Por outro lado, como os dados brutos (abertos) são pouco mediados, eles reduzem as oportunidades para que os funcionários oficiais (burocratas) manipulem os dados de acordo com as motivações profissionais ou políticas. Além disso, dados brutos são fáceis de reorganizar, uma vez que se referem à informação que é a mais próxima da fonte, permitindo aos usuários visualizá-las diretamente por meio da internet, atraindo o interesse de um número maior de pessoas. Informação bruta, no entanto, não é isenta de problemas e uma de suas fraquezas fundamental é o viés de regulação, em que apenas parte das informações tornase visível, reduzindo e, até mesmo, eliminando a capacidade de os usuários fazerem inferências com base nesse conjunto de dados (MICHENER; BERSCH, 2011).

No intuito de facilitar a compreensão do leitor, o Quadro 1 tem por objetivo sintetizar as diversas classificações apresentadas anteriormente.

Quadro 1 - Classificações da Transparência quanto à direção, à variedade, à iniciativa e às dimensões conceituais

\begin{tabular}{|l|l|}
\hline Quanto à direção & Vertical - Transparência para cima e Transparência para baixo \\
\cline { 2 - 2 } & Horizontal - Transparência para fora e Transparência para dentro \\
\hline \multirow{2}{*}{ Quanto à variedade } & Transparência de Eventos e Transparência de Processos \\
\cline { 2 - 2 } & Transparência Retroativa e Transparência Tempestiva \\
\cline { 2 - 2 } & Transparência Nominal e Transparência Efetiva \\
\hline Quanto à iniciativa & Transparência Ativa e Transparência Passiva \\
\hline Quanto às dimensões conceituais & Visibilidade e Capacidade de inferência \\
\hline
\end{tabular}

Fonte: Elaborado pelos autores.

Mesmo diante das classificações apresentadas, o que certamente é um grande esforço para a identificação do conceito de transparência, não está claro, ainda, o que significa o termo transparência. Em geral, o conceito de transparência está associado ao fluxo informacional, mas seu uso por diversos pesquisadores, em diversos campos do conhecimento, tem levado o termo, como destacado, a um alongamento conceitual e a um neologismo impreciso e incomunicável.

Isso se verifica em um bom número de trabalhos e entidades que, ao se proporem a avaliar a transparência, acabam intercambiando análises de coisas distintas. Em geral, pesquisas aglutinam aspectos orçamentários e de compras, contábeis e orçamentários, orçamentários e institucionais, etc., e não contemplam as diversas classificações anteriormente apresentadas.

Isso decorre, na maioria das vezes, por causa da falta de delimitação de uma perspectiva conceitual que permita aos pesquisadores realizar suas abordagens analíticas quanto às diversas classificações, direções, variedades e dimensões conceituais. Buscando contribuir para o avanço do conceito, das classificações e da delimitação do escopo analítico, apresenta-se, a seguir, a classificação da transparência dentro do que denominamos de perspectivas analíticas da transparência.

\subsubsection{As diversas perspectivas analíticas da transparência}

A diversidade de conceitos tem gerado muitas confusões conceituais e transposição do conceito entre as diversas perspectivas da transparência. Boa parte dos trabalhos junta em suas análises a transparência orçamentária, do processo de compras, institucional, social, dos contratos, entre outras. Buscando contribuir com o esclarecimento das dimensões, 
apresentam-se, a seguir, algumas dessas perspectivas, suas definições e o que as compõem. A intenção não é esgotar as possíveis perspectivas, mas contribuir para a especificação, definição e análise das que, normalmente, são mais investigadas.

Essas perspectivas foram definidas por esses autores levando-se em consideração trabalhos realizados pela Transparência Internacional, pelo International Budget Partnership e por trabalhos que se dedicaram a avaliar os níveis de transparência, tanto no contexto nacional, como no internacional, como (CRUZ et al., 2012; PINHO, 2008; RIBEIRO; ZUCCOLOTTO, 2014; ZUCCOLOTTO; TEIXEIRA, 2014).

A transparência sob a Perspectiva Orçamentária consiste na evidenciação de todas as informações orçamentárias relevantes de maneira sistemática e tempestiva e que permitam ao cidadão, além de visualizá-las, fazer inferências a partir delas. Assim, a transparência, sob a perspectiva orçamentária, preocupa-se exclusivamente com a análise do processo orçamentário.

Nesse sentido, analisa-se o ciclo orçamentário, desde o planejamento até o parecer prévio dos Tribunais de Contas. Também é possível analisar apenas parte do ciclo, mas é importante que isso seja claro e bem delimitado no escopo da pesquisa.

Os documentos que devem ser analisados podem sofrer variações entre os países, mas, no caso brasileiro, incluem: Relatórios pré-orçamentários (PPA, LDO), Proposta orçamentária do executivo, Orçamento cidadão, Orçamento aprovado, Relatórios de acompanhamento da execução orçamentária, Relatórios intermediários (RREO e RGF), Relatório de fim de ano (Balanço Orçamentário) e Relatórios de auditoria (Parecer Prévio dos Tribunais de Contas).

Sob a Perspectiva Contábil, a transparência consiste na evidenciação de todas as informações patrimoniais e financeiras de maneira sistemática e tempestiva, de forma que o usuário possa, além de acessá-las, avaliar as capacidades econômica, financeira e patrimonial dos entes. Além disso, nessa perspectiva, a sociedade pode conhecer os regimes contábeis adotados pelos governos (caixa ou competência), as principais políticas contábeis adotadas, as mudanças de critérios, etc.

Nessa perspectiva, deve-se, minimamente, avaliar: Balanço Patrimonial, Balanço Financeiro, Demonstração das Variações Patrimoniais, Demonstração de Fluxos de Caixa, Demonstração das Mutações do Patrimônio Líquido, Divulgação das Principais políticas contábeis do ente, notas explicativas às Demonstrações Contábeis e quadros auxiliares (como, por exemplo, relação de bens de valor histórico). Deve-se incluir, também, nesse conteúdo mínimo, o relatório de auditoria, seja ele emitido por entidade independente ou por uma Instituição Suprema de Auditoria.

A transparência sob a Perspectiva Institucional ou Organizacional consiste na evidenciação de todas as informações sobre a organização do Estado, cargos e responsabilidades, além de normas e relatórios. Uma vez que os Estado possuem uma estrutura organizacional ampla e complexa, pode-se recorrer a duas possibilidades. A primeira consiste em evidenciar os órgãos centrais de governos para em seguida, uma vez acessado o órgão desejado, acessar os órgãos subordinados. Isso poderia se dar por meio de links para cada órgão componente do órgão central.

Os documentos que normalmente devem ser analisados nessa dimensão são: Organograma do Estado (executivo, legislativo e judiciário) com definição de cargos, funções, responsabilidades e formas de contato dos órgãos e dos seus respectivos chefes. Deve-se observar, também, a disponibilidade de informações sobre o número de servidores dos órgãos, segregados por cargos eleitos, nomeados e concursados. Além disso, avalia-se, 
também, a disponibilidade de acesso às legislações, normas, atas e aos relatórios dos governos e fluxogramas de processos.

Essa forma de transparência deve reunir, ainda, informações sobre o órgão finalístico da política ou do serviço público, por exemplo, dentro do Ministério da Saúde, deverá haver a descrição dos hospitais por estado com a definição das especialidades, os nomes dos médicos que atuam na unidade e o número de leitos. O mesmo raciocínio se aplica ao Ministério da Educação, entre outros.

Essas informações, além de desempenharem um papel social importante, visto que permitem à sociedade identificar serviços médicos especializados próximos a suas casas, auxiliam também o próprio estado na implantação de ferramentas que permitam ao cidadão monitorar o funcionamento dos serviços naquelas unidades. $\mathrm{O}$ mesmo se aplica a diversas outras secretarias e ministérios.

A transparência sob a Perspectiva Social ou Cívica consiste na existência de mecanismos de informação e atenção ao cidadão e compromisso com a cidadania. Assim, além de informações sobre atividades culturais e cívicas, é importante que os governos desenvolvam e estimulem canais para sugestão, denúncias e participação do cidadão e da sociedade civil organizada.

Nesse sentido, a análise nessa dimensão compreende: horários de funcionamento dos estabelecimentos culturais, existência de mecanismos de participação e acompanhamento de audiências públicas, existência de fóruns, existência de espaço para as associações sem finalidade de lucros divulgarem suas informações, existência de informações sobre os conselhos, sua organização, função, responsáveis e responsabilidades, metas, avaliação de desempenho e formas de participação.

A transparência sob a Perspectiva do processo licitatório consiste na divulgação de informações sobre a contratação de obras, materiais e serviços por parte dos governos, bem como informações sobre o fluxo desse processo, valores, concorrentes e resultados. A finalidade é permitir que a sociedade civil acompanhe os processos de compras, monitore-o e avalie-o ao final do processo.

De forma geral, o conteúdo mínimo a ser avaliado é composto por editais de contratação de obras, materiais ou serviços, bem como mapas e plantas quando se tratar de obras, organograma de execução da obra, órgão e servidor responsável pelo processo de compra, atas com os resultados do processo, recursos impetrados pelos concorrentes, resultados dos recursos, vencedor do processo, lista de vencedores de processos de licitação nos últimos exercícios, lista de recursos impetrados, organograma revisado de execução quando se tratar de obras.

A transparência sob a Perspectiva de contratos e convênios consiste na divulgação dos contratos, convênios, termos de parceria e de cooperação estabelecidos por um governo.

O objetivo dessa perspectiva da transparência é permitir à sociedade conhecer as partes envolvidas nos contratos, as responsabilidades de cada uma das partes, as ferramentas de monitoramento, a forma de avaliação de desempenho, as penalidades, etc.

O conteúdo mínimo a ser divulgado nessa perspectiva envolve as atribuições de responsabilidades nos contratos, os convênios e termos de parceria, as medidas de avaliação de desempenho, os prazos e valores e as cláusulas de penalidades.

Sob a Perspectiva Midiática, a transparência consiste na avaliação de uma ou mais dimensões da transparência descritas anteriormente, todavia em meio eletrônico de acesso 
público. Esses meios podem variar desde a divulgação em páginas da $W e b$ até aplicativos para celulares, smartphones e tablets.

No que se refere aos itens a avaliar, esses podem consistir dos itens descritos nas perspectivas anteriormente descritas, como também podem incluir aspectos específicos de mídia e tecnologia.

Como se observa, existem diversas perspectivas para a transparência, sendo que cada uma delas é conceitualmente diferente e as formas de mesurá-las também. Nesse sentido, é fundamental que a elaboração de pesquisas que envolvam o tema transparência tenham preocupação em estabelecer a perspectiva de forma correta, tanto do ponto de vista conceitual como de sua classificação, sob pena de termos transposições de conceitos e medidas que prejudiquem a qualidade da análise ou até mesmo a inviabilizem.

Não menos importante é a correta classificação da transparência quanto às suas direções, variedades, iniciativa, dimensões conceituais e perspectivas. Como já destacado, essas classificações não esgotam o tema, mas acredita-se que essa revisão da literatura e a proposição de perspectivas analíticas sejam um ponto de partida importante no sentido de ordenar os diversos conceitos e classificações da transparência de forma a reposicionar o debate sobre ela, uma vez que a correta classificação, a interpretação e a análise permitem reposicionar a compreensão das práticas e da realidade, contribuindo, dessa forma, para a continuidade da pesquisa, do debate e da compreensão desse tema no Brasil.

\section{Considerações Finais}

Como já estabelecido na introdução, esse trabalho teve por objetivo realizar uma revisão da literatura internacional sobre conceitos e as classificações da transparência e propor uma classificação desse tema em diversas perspectivas. $\mathrm{O}$ objetivo, tanto da revisão quanto da proposição das perspectivas, é ampliar o conhecimento sobre esse campo de investigação e, por consequência, permitir maior precisão conceitual e classificatória aos estudos sobre o tema.

Como visto, a definição da transparência ainda está em construção, mas muito já se avançou na literatura internacional sobre conceituações, definições e classificações. Mesmo com todo esse avanço, a busca pelo esclarecimento do que é transparência ainda continua, mas o que não pode ocorrer - e com certa frequência vem ocorrendo - é a realização de trabalhos que assumem a transparência como algo entendido, dado que está subentendido na mente ou no coração das pessoas. Para a continuidade e aperfeiçoamento do sentido da transparência, sua compreensão, classificação e, por fim, sua definição, torna-se imperativo que, sobretudo, os pesquisadores percebam a necessidade de delimitação do campo de pesquisa, da classificação da transparência quanto às direções, às variedades, à iniciativa, às dimensões conceituais e às perspectivas.

Maior precisão acerca da conceituação e classificação entre as diversas "anatomias da transparência" certamente possibilitará melhor compreensão do seu sentido, das suas potencialidades e contribuição para a consolidação democrática. Conhecer os limites e potencialidades da transparência é de fundamental importância nas pesquisas que tratam de uma ordem democrática, no entanto essa compreensão só será efetiva quando interposta em um quadro conceitual objetivo e cujas definições e classificações sejam claras. 
O caminho está iniciado, resta agora avançar. Esse avanço abre caminhos e possibilidades para maior diversidade de pesquisas que almejem não apenas conceituar e classificar a transparência, mas também compreendê-la, dentro das definições e classificações já conhecidas, como ela opera, quais as principais diferenças entre países com estruturas democrático-institucionais distintas, como ela opera em âmbito subnacional, qual o papel da regulação nesse processo, etc.

Resta assim a ação, ou como diria Maquiavel, a virtù, uma vez que sem ela os avanços até agora obtidos não seriam possíveis, como também não serão os que ainda estão por vir, os quais resultarão do fruto da virtù dos pesquisadores.

\section{Referências}

AKUTSU, L.; PINHO, J. A. G. DE. Sociedade da informação, accountability e democracia delegativa: investigação em portais de governo no Brasil. Revista de Administração

Pública, v. 36, n. 5, p. 471-493, 2002.

]BESSETTE, J. M. Accountability: Political. In: SMELSER, N. J.; BALTES, P. B. (Eds.). . International Encyclopedia of the Social \& Behavioral Sciences. Amsterdam: Elsevie, 2001. p. 38-41.

BIRKINSHAW, P. Freedom of information and openness: fundamental human rights. Administrative Law Review, v. 58, n. 1, p. 177-218, 2006.

BLACK, J. Transparent Policy Measures. In: BLACK, J. (Ed.). . Oxford Dictionary of Economics. Oxford: Oxford University Press, 1997.

CAMPOS, A. Accountability: quando poderemos traduzi-la para o português? Revista de Administração Pública, v. 24, n. 2, p. 30-50, 1990.

CRUZ, C. F. et al. Transparência da gestão pública municipal: um estudo a partir dos portais eletrônicos dos maiores municípios brasileiros. Revista de Administração Pública, v. 46, n. 1, p. 153-176, fev. 2012.

DAHL, R. A. Poliarquia: Participação e oposição. São Paulo: Editora USP, 2012.

FUNG, A.; GRAHAM, M.; WEIL, D. Full Disclosure: The Perils and Promise of Transparency. New York: Cambridge University Press, 2007.

GRIGORESCU, A. International Organizations and Government Transparency: Linking the International and Domestic Realms. International Studies Quarterly, v. 47, n. 4, p. 643-667, dez. 2003.

HEALD, D. Fiscal Transparency: Concepts, Measurement and UK Practice. Public Administration, v. 81, n. 4, p. 723-759, dez. 2003. 
HEALD, D. Vaieties of transparency. In: HOOD, C.; HEALD, D. (Eds.). . Transparency. The key to better governance. New York: Oxford University Press, 2006. p. 25-43. HOOD, C. Transparency in historical perspective. In: HOOD, C.; HEALD, D. (Eds.). . Transparency: The Key to Better Governance? New York: Oxford University Press, 2006. p. 3-23.

KING, G.; KEOHANE, R. O.; VERBA, S. Designing Social Inquiry: Scientific Inference in Qualitative Research. New Jersey: Princeton University Press, 1994.

KRASNER, S. D. Causas estruturais e consequências dos regimes internacionais: regimes como variáveis intervenientes. Revista de Sociologia e Política, v. 20, n. 42, p. 93-110, jun. 2012.

LARSSON, T. How open can a government be? The Swedsh experience. In: DECKMYN, V.; THOMSON, I. (Eds.). . Openness and transparency in the European Union. Maastricht, Netherlands: European Institute of Public Administration, 1998. p. 169.

LOUREIRO, M.; TEIXEIRA, M.; PRADO, O. Construção de instituições democráticas no Brasil contemporâneo: transparência das contas públicas. Revista Organização \& Sociedade, v. 15, n. 47, p. 107-119, 2008.

MEIJER, A. Understanding modern transparency. International Review of Administrative Sciences, v. 75, n. 2, p. 255-269, 19 jun. 2009.

MICHENER, G.; BERSCH, K. Conceptualizing the quality of transparency. Political Concepts, v. 49, p. 1-27, 2011.

MOSER, C. How open is "open as possible"? Three different approaches to transparency and openness in regulating access to EU documents. IHS Political Science Series, v. 80, 2001.

NOLAN COMMITTEE. First Report of the Committee on Standards in Public Life., 1995. Disponível em: <http://www.public-standards.gov.uk/> Acesso em:

O’DONNELL, G. Accountability horizontal e novas poliarquiasLua Nova, 1998.

Disponível em: <http://www.scielo.br/pdf/ln/n44/a03n44> Acesso em:

PINHO, J. A. G. DE; SACRAMENTO, A. R. S. Accountability: já podemos traduzi-la para o português? Revista de Administração Pública, v. 43, n. 6, p. 1343-1368, dez. 2009.

PINHO, J. Investigando portais de governo eletrônico de estados no Brasil: muita tecnologia, pouca democracia. Revista de Administração Pública (RAP), Rio de ..., v. 42, n. 3, p. 471493, 2008.

POSTMAN, N. Technopoly: The Surrender of Culture to Technology. New York: Vintage Books Edtion, 1993. 
PRADO, O.; RIBEIRO, M. M.; DINIZ, E. Governo eletrônico e transparência: olhar crítico sobre os portais do governo federal brasileiro. In: PINHO, J. A. G. (Ed.). . Estado, sociedade e interações digitais: expectativas democráticas. Salvador: Editora EDUFBA, 2012. p. 1339.

PRZEWORSKI, A.; STOKES, S. C.; MANIN, B. Democracy Accountability And Representation. Cambridge: Cambridge University Press, 1999.

RIBEIRO, C. P. D. P.; ZUCCOLOTTO, R. The hidden face of Leviathan: fiscal transparency in brazilian municipalities and its socioeconomic determinants and tax. Enfoque: Reflexão Contábil, v. 33, n. 1, p. 37-52, jan. 2014.

SCHULTZ, K. A. Do Democratic Institutions Constrain or Inform? Contrasting Two Institutional Perspectives on Democracy and War. International Organization, v. 53, n. 2, p. 233-266, 1 abr. 1999.

WHITE, F.; HOLLINGSWORTH, K. Audit, Accountability and Government. New York: Oxford University Press, 1999.

YAZIGI, A. F. Dinero, política y transparencia: El imperativo democrático de combatir la corrupción. 9th International Anti-Corruption Conference (IACC), p. 10-15, 1999.

ZUCCOLOTTO, R.; TEIXEIRA, M. A. C. The Causes of Fiscal Transparency: Evidence in the Brazilian States. Revista Contabilidade \& Finanças, v. 25, p. 242-254, 2014. 